\title{
Beyond Category
}

\section{ONCE A NICHE ACTIVITY, ESG INVESTING IS CROSSING ASSET CLASSES}

By Sherree DeCovny

Investing based on environmental, social, and governance (ESG) factors turned into mainstream investing so fast many investors may not have noticed the transformation. While screening out controversial sectors used to be limited to a smaller subgroup of investors motivated by a focus on social responsibility, many investors now have a real appreciation for the value of ESG research and what it brings to the investment process. To go along with this chang-

With substantial gains in assets under management, ESG investing's growing popularity has driven improvements in data reporting and financial metrics, among other trends that are changing the game for analysts and investors.

Across industries, managers of many companies increasingly believe ESG factors can improve business strategies, improve operational efficiency, drive revenue growth, and manage risk.

Although some studies have suggested marginal outperformance associated with ESG strategies, experts highlight the stronger case that there is no performance penalty for ESG investing. are examples of two recently established brands focused on sustainable investing. The Parnassus Endeavor Fund is a value fund that picks stocks from a pool of companies that have been identified as good workplaces. It avoids companies engaged in the extraction, exploration, production, manufacturing, or refining of fossil fuels. Goldman Sachs bought Imprint Capital, an impact investing firm; Morgan Stanley has its Institute for Sustainable Investing; Bain Capital created the Double Impact Fund; and there are many others.

Awareness among real estate investors is increasing as well, because valuable property is often located in coastal regions that are being affected by climate change. For example, Miami Beach has a $\$ 400$ million plan to raise streets, install pumps, and elevate sea walls. Fort Lauderdale is also spending millions to fix roads and drains and send out trucks to vacuum saltwater from the streets.

For investors, however, an overarching concern is about any potential tradeoff in performance. Some data suggest marginal outperformance associated with certain ESG strategies, but even if the past outperformance has been real, the question for investors is always how to analyze the prospect of future performance.

\section{BETTER REPORTING}

Ongoing efforts to improve the quality of ESG reporting and financial metrics "will be a great assistance to analysts as they engage in integration of ESG factors into the evaluation of companies," says Steve Lydenberg, CFA, partner for strategic vision at Domini Impact Investments in Providence, Rhode Island.

ESG reporting has been driven in part by the work of the Global Reporting Initiative, an international independent standards organization, headquartered in Amsterdam, which has developed the Sustainability Reporting Guidelines, a "globally shared framework of concepts, consistent language, and metrics" that "can be used by organizations of any size, sector, or location." But, ESG data are available more widely now than ever. For example, $\mathrm{ESG}<\mathrm{GO}>$ is a Bloomberg Terminal function that provides investors with data about a company's ESG metrics, such as greenhouse 
gas emissions intensity, resource consumption, and workplace diversity. The function provides an overview of a company's support of sustainability initiatives and ranks its performance compared with industry peers.

Moreover, as ESG data becomes more sophisticated, more detailed, and easier to analyze, the trend is toward incorporating key performance indicators (KPIs), particularly into public equity analysis. There is also a corresponding move toward ESG integration-integrated accounting of financial and non-financial data so analysts do not have to sift through many different reports to find it.

An initiative known as Project Delphi is being coordinated by State Street Global Advisors in the US, but a strong European base is engaged in a similar exercise. That is happening simultaneously with the campaign led by the International Integrated Reporting Council, whose goal is to ensure that the ESG KPIs under development are reported in the same format and the same way as financial metrics.

Issues such as climate change cut across most industries. According to the Sustainability Accounting Standards Board, a San Francisco-based organization incorporated in 2011 "for the purpose of establishing industry-based sustainability standards for the recognition and disclosure of material," climate change affects 72 out of the 79 industries for which it provides industry-specific KPIs (93\% of the capital markets, or $\$ 27.5$ trillion) - although its effects manifest differently from one industry to the next.

\section{INVESTING IN PEOPLE, NOT IDEAS}

"At the end of the day, people invest in management," says Michael Greis, CFA, principal, Riverbend Advisors. "Venture capitalists will tell you, 'It's not the idea we invest in, because the idea will probably change before it comes to market. It's the quality of the people and the management team."'

On the social side of ESG, employee relations (a category that encompasses diversity) cuts across most, if not all, industries. Some researchers believe the quality of employee relations is among the metrics most closely tied to financial performance. Studies by Daniel Koys, a professor of management at DePaul University, and others suggest that employee satisfaction-defined as providing better pay, ongoing training, and making employees feel securehelps companies achieve financial goals. The logic is that if a company takes care of its employees, the employees will be motivated to take care of the customers. This is especially relevant in businesses such as hospitality management and tourism.

In terms of governance, how companies handle crises sheds light on the quality of management. Some investors argue that corporate crises may stem from poor corporate culture, although both are difficult to quantify.

Nearly $40 \%$ of all shareholder proposals submitted at Russell 3000 companies that held meetings during the first half of 2014 were related to social and environmental policy issues, according to the Conference Board. This number was up from 29\% in 2010, as documented in "Proxy Voting Analytics (2010-2014)." Social and environmental policy proposals represent the second-largest category of the subjects submitted and voted on-narrowly behind corporate governance.

Going beyond conventional concerns about "governance," a key development is that ESG factors increasingly are being built into corporate strategy to drive revenue growth, ensure strong supply chain models, manage risk, and satisfy customers.

To illustrate, consider the example of Diageo, a British company with a portfolio of alcoholic beverage brands (including Guinness beer) that sources barley from Kenya. Climate change is having an impact on rainfall in that region, so water management is critical. The company claims that its water efficiency has improved by $30 \%$ over the past decade, with water efficiency of its operations in Africa improving more than $40 \%$ during the same period. Identifying water as "our biggest environmental priority," the company has multiple new targets for water replenishment as part of its 2020 Sustainability \& Responsibility strategy.

Diageo's story is clearly part of a larger corporate trend. For example, McDonald's CEO Steve Easterbrook has commented publicly that the company's sheer purchasing power has an influence, and the goal is to use its size and scale for good, such as helping farmers and improving agricultural practices.

Like Easterbrook, managers of many companies in a variety of industries believe that working on an agenda that customers care about may entice them to visit more often, as well as attract new customers and strengthen the brand. An interesting case study is Praxair, an industrial gas company. In December 2016, Praxair was named to the new Climate A-List by CDP, recognizing actions Praxair has taken to manage its own carbon footprint and that of its customers. This is the ninth consecutive year that Praxair has been named to a CDP list or index.

"Praxair has a companywide system that helps track the benefits of its sustainability initiatives," says Fernandez. "They're one of the few that we found that actually can track the cost savings from energy efficiency improvements and others on an aggregate basis."

In 2015, Praxair implemented global projects that, among other benefits, enabled customers or their end users to avoid more than two times the greenhouse gas emissions than were emitted in all of Praxair's operations. Additionally, since 2010, the company has achieved a cumulative $\$ 260$ million savings in energy efficiency, including avoiding \$1.4 million in megawatt hour electricity and \$2.1 million in carbon dioxide equivalent. This increased efficiency contributed directly to Praxair's operating results.

\section{"A VERY POSITIVE THING"}

There are more than 100 ESG rating providers or rankings globally. The Newsweek Green Rankings, for example, lists 
companies based on environmental performance. The Dow Jones Sustainability Index has certain criteria that companies need to meet to get listed. Moreover, Sustainalytics has teamed up with Morningstar to rate funds based on their underlying ESG characteristics. These ratings and rankings vary significantly depending on the provider. However, they are a starting point for further investigation and discussions with companies.

"They're not intended, nor should they be looked at, as a seal of approval that says, 'You can invest in this; you can't invest in that," says Greis. "That said, ratings and rankings provide valuable information. The arrival of fund ratings from major providers like Morningstar/Sustainalytics and MSCI has changed the conversation and introduced the concept to more people. That's a very positive thing." [For a more detailed analysis of rating investment funds based on ESG characteristics, see "Sustainability Scores for Investment Funds" in the Viewpoint section on page 26.]

Innumerable studies have taken various approaches to assess the correlation between high levels of ESG commitment and performance. Overall, they conclude that there is no performance penalty for ESG integration and it is possible to achieve risk-adjusted returns similar to a traditional portfolio.

Moreover, the Quantitative Portfolio Strategy Research team at Barclays published a study titled "Sustainable Investing and Bond Returns," which looks at the relationship between ESG investing performance and the US corporate-bond market. The research shows that introducing ESG factors in the investment process resulted in a small but steady performance benefit, particularly when adjusted for risk or volatility. The research also notes that of the three components of ESG, the governance score had the strongest impact on performance. Bonds with high governance scores suffered credit downgrades less often than those with a low governance score.

"In our own research, we have determined that there has not been a significant difference in performance in our sustainable strategies that emphasize ESG versus our traditional strategies at Breckinridge," says Fernandez. "Based on Barclays' study and our own findings, an investor can invest responsibly and potentially not give up return."

Another study, published in 2015 by Harvard Business School ("Corporate Sustainability: First Evidence on Materiality"), found that companies that did a better job managing sustainability performance and the SASB standards had better equity performance.

Lydenberg has been involved in two exercises that show marginal outperformance, though he notes that on a riskadjusted basis, neither is probably statistically significant. One exercise was the creation of the Domini Social Index in 1990, which is now called the MSCI KLD 400 Social Index. It compares a socially screened index to a nonsocially screened index. Generally, there is marginal outperformance on a non-risk-adjusted basis of less than 100 basis points.

\section{Standardization Challenges}

According to the Governance \& Accountability Institute, $20 \%$ of companies in the S\&P 500 published a sustainability report in 2011. By 2015, the number had increased to $81 \%$. It is conceivable that in the future, all companies will have to publish a sustainability report to show investors how they are managing these material risks.

"A lot of this is information that many people aren't using yet," says Michael Greis, CFA, principal, Riverbend Advisors. "By its very definition, it is the kind of asymmetric information that analysts and portfolio managers have always wanted to find. They want to understand something about companies, investments, or industries that others don't get."

It's not atypical for a corporate sustainability report to be around 150 pages long. Analysts only have so much time to devote to researching a particular company, and at some point they will need to move on to the next one. This is why the Sustainability Accounting Standards Board's (SASB) efforts to collect and disclose ESG data in a cost-effective, consistent, and comparable way are so important in reducing both information overload for analysts and the reporting burden on companies.

SASB requests that companies report metrics based on certain topics: An industrial manufacturer could be asked to report on carbon emissions because that is a material issue for the sector, for example. As part of that topic, companies could be asked to report greenhouse gas emissions based on a certain metric. However, some companies in the sector may choose not to report on it.

"If every company in the sector reports the same thing, you can easily compare one to another from a performance standpoint," says Robert Fernandez, CFA, director of ESG research at Breckinridge Capital Advisors, which manages about $\$ 26.5$ billion in municipal and corporate bonds. "Just like you could look at revenue, margins, leverage, and cash flow to see how one company is performing versus another, you would in theory be able to do that with sustainability reporting."

"The marginal outperformance reflects the fact that some of these factors are not yet taken into account," he says. "In the long run, as these factors become taken into account by more investors, I would expect that even that marginal outperformance will just get arbitraged away."

Ultimately, investors need to consider a different kind of sustainability when evaluating companies. As Greis says, "If

KEEP GOING

Brush up on ESG investing and earn CE credit: www.cfainstitute.org/RefreshMySkills they go away, then it doesn't really matter how good a company you invested in."

Sherree DeCovny is a freelance journalist specializing in finance and technology. 